\title{
Sulfide mineralization is induced by shallow intrusion on the ultraslow- spreading Southwest Indian Ridge: Sulfide mineralogy and geochemistry evidence from the Longqi-3 hydrothermal field
}

\author{
Shili Liao ${ }^{1,2}$, Chunhui Tao ${ }^{1,2 *}$, Jin Liang ${ }^{1,2}$, \\ Weifang Yang ${ }^{1,2}$, Jia Liu ${ }^{1,2}$, Wei $\mathrm{Li}^{1,2}$ \\ 1. Second Institute of Oceanography, Ministry of Natural \\ Resources, Hangzhou 310012, Zhejiang, China; \\ ${ }^{2}$ Key Laboratory of Submarine Geosciences, State Oceanic \\ Administration, Hangzhou 310012, China;
}

The newly discovered Longqi-3 hydrothermal field (HF) is located on the ultraslow-spreading Southwest Indian Ridge. Sulfide-rich samples collected from this field exhibit stockwork mineralization, which is primarily seen on ultraslow-spreading ridges, presenting an opportunity to understand the subsurface mineralization characteristics and diversity of the hydrothermal activity in ultraslow-spreading ridges. Sulfide mineralization in this field can be divided into stockwork, semi-massive, and oxidation stages. The stockwork stage mainly comprised pyrite, chalcopyrite, magnetite, hematite, and ilmenite. However, the semimassive stage mainly comprised chalcopyrite, pyrite, pyrrhotite, and minor sphalerite. The $\mathrm{Cu}$ contents of the sulfide-rich samples were in the range of 0.02-2.88 wt.\% with an average of $0.37 \mathrm{wt} . \%$, and the $\mathrm{Zn}$ content was generally below $0.01 \mathrm{wt} . \%$. The chemical compositions of the sulfide-rich samples suggested that the ore-forming elements were probably of basaltic origin. The sulfur isotopes content in the sulfide-rich samples was $4.42-11.28 \%$ and averaged $7.61 \%$. The mineral assemblages and sulfur isotope features indicated that the deep part of the hydrothermal system is in an oxidation environment and has a high permeability that allows large quantities of seawater to enter. During the oreforming process, the conditions shifted from relatively oxidizing to more reducing conditions and, accordingly, the seawater-derived sulfur in the system deceased from $46.41 \%$ to $41.90 \%$ and subsequently to $31.85 \%$. Hence, the Longqi-3 HF probably formed by the intrusion of a shallow dike into the normal fault system. This finding implies that HFs that are controlled by shallow heat sources may have developed on other ultraslow-spreading ridges. 